DOI: 10.20472/IAC.2018.042.015

\author{
ELENA GRIGORIEVA \\ RUDN University, Russian Federation \\ DARYA KARPOVA \\ RUDN University, Russian Federation
}

\title{
THE USE OF THE MECHANISM OF TAX INCREMENT FINANCING (TIF) IN THE FINANCING OF INFRASTRUCTURE PROJECTS
}

\begin{abstract}
:
The article presents an analysis of the foreign experience of the mechanism of tax increment financing (TIF) in the financing of infrastructure projects and assesses the possibility of implementing this mechanism in the Russian investment practice.

Investment in infrastructure development is an important factor in the socio-economic development of the country and has a multiplier effect. In the world practice, the involvement of private capital in the creation and subsequent operation of infrastructure facilities contributes to the sustainable growth of the national economy, the introduction of promising technological, organizational and institutional innovations, resource saving and energy independence, improving the quality of services provided to the population.

The problem of efficiency of joint investment activity of private and public capital owners in infrastructure projects is due to the complexity of taking into account the interests of all participants. The format of joint activities should be based on the principles of risk sharing, connection of projects with the target socio-economic characteristics of the development of territories, obtaining benefits from the results of projects.

The authors studied the most successful practices of infrastructure development financing, taking into account possible future benefits from the creation of these facilities in the form of additional revenues from taxes, fees, access rights to the operation of infrastructure and other privileges. One of these tools is the mechanism of tax increments of financing.

The paper analyzes the conditions for the implementation and fulfillment of this mechanism in different countries of the world, studied the experience of the TIF mechanism, taking into account industry specifics and other features of the projects, describes the specific models of the TIF mechanism.

The comparative approach and macroeconomic analysis were used to compare the conditions of implementation of the TIF mechanism and project financing, and to identify fundamental similarities and differences. The conclusion is made about the possibility of embedding (diffusion) of individual elements of the TIF mechanism in project financing in Russia.

The use of institutional and statistical analysis, as well as the methodology for assessing the effectiveness of investment projects, allowed the authors to form a comprehensive assessment of the possibility of using the TIF mechanism in the Russian environment.
\end{abstract}

\section{Keywords:}

tax increment financing, TIF, investments, project finance, infrastructure development, public-private partnership 
JEL Classification: E62, O22, 018 